\title{
Use of Endocrine Therapy for Breast Cancer Risk Reduction: ASCO Clinical Practice Guideline Update
}

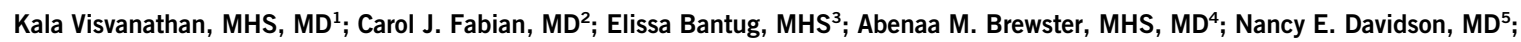 \\ Andrea DeCensi, MD ${ }^{6}$; Justin D. Floyd, DO'; Judy E. Garber, MPH, MD ${ }^{8}$; Erin W. Hofstatter, MD ${ }^{9}$; Seema A. Khan, MD ${ }^{10}$; \\ Maria C. Katapodi, PhD ${ }^{11}$; Sandhya Pruthi, MD ${ }^{12}$; Rachal Raab, MD ${ }^{13}$; Carolyn D. Runowicz, MD ${ }^{14}$; and Mark R. Somerfield, PhD ${ }^{15}$
}

ASSOCIATED CONTENT

Appendix

Data Supplement

Author affiliations and support information (if applicable) appear at the end of this article.

Accepted on May 31, 2019 and published at jco.org on

September 3, 2019: Dol https://doi.org/10. 1200/JC0.19.01472

K.V. and C.J.F. were Expert Panel co-chairs and co-first authors on the update.

Clinical Practice Guidelines

Committee approval: May 28, 2019.

Reprint Requests: 2318 Mill Rd, Suite 800, Alexandria, VA 22314; guidelines@ asco.org

PURPOSE To update the ASCO guideline on pharmacologic interventions for breast cancer risk reduction and provide guidance on clinical issues that arise when deciding to use endocrine therapy for breast cancer risk reduction.

METHODS An Expert Panel conducted targeted systematic literature reviews to identify new studies.

RESULTS A randomized clinical trial that evaluated the use of anastrozole for reduction of estrogen receptor-positive breast cancers in postmenopausal women at increased risk of developing breast cancer provided the predominant basis for the update.

UPDATED RECOMMENDATIONS In postmenopausal women at increased risk, the choice of endocrine therapy now includes anastrozole ( $1 \mathrm{mg} /$ day) in addition to exemestane $(25 \mathrm{mg} /$ day), raloxifene $(60 \mathrm{mg} /$ day $)$, or tamoxifen (20 mg/day). The decision regarding choice of endocrine therapy should take into consideration age, baseline comorbidities, and adverse effect profiles. Clinicians should not prescribe anastrozole, exemestane, or raloxifene for breast cancer risk reduction to premenopausal women. Tamoxifen $20 \mathrm{mg} / \mathrm{day}$ for 5 years is still considered standard of care for risk reduction in premenopausal women who are at least 35 years old and have completed childbearing. Data on low-dose tamoxifen as an alternative to the standard dose for both pre- and postmenopausal women with intraepithelial neoplasia are discussed in the Clinical Considerations section of this article. Additional information is available at www.asco.org/breast-cancer-guidelines.

$\mathrm{J}$ Clin Oncol 37:3152-3165. @ 2019 by American Society of Clinical Oncology

\section{INTRODUCTION}

ASCO first published clinical practice recommendations for the use of pharmacologic interventions for breast cancer risk reduction in $1999 .{ }^{1}$ ASCO updated these breast cancer risk reduction guideline recommendations in 2002, 2009, and 2013.2-4 The current update was undertaken to integrate data from the International Breast Intervention Study-II (IBIS-II) randomized, placebo-controlled trial on the use of anastrozole ( $1 \mathrm{mg} /$ day orally for 5 years) to reduce the incidence of breast cancer in postmenopausal women at increased risk of developing breast cancer. ${ }^{5}$

This guideline summarizes the results of a literature search and review of new data on breast cancer risk reduction published since 2013 and provides new recommendations for the use of anastrozole in breast cancer risk reduction. These new recommendations supplement the guideline recommendations issued in 2013.

In addition, as a result of discussions of clinical considerations, this update addresses some questions frequently raised by patients and/or providers regarding the use of tamoxifen, raloxifene, or an aromatase inhibitor for breast cancer risk reduction. The recent placebo-controlled trial of a lower dose of tamoxifen ( $5 \mathrm{mg} /$ day) for 3 years in women with intraepithelial neoplasia (atypical hyperplasia or in situ cancer) is also reviewed. ${ }^{6}$

\section{FOCUSED UPDATE GUIDELINE QUESTION}

This guideline update addresses the following clinical question: What is the role of anastrozole in reducing the risk of developing breast cancer in women not previously diagnosed with breast cancer?

\section{METHODS}

\section{Guideline Update Process}

ASCO uses a signals approach to facilitate guideline updating. ${ }^{7}$ This approach identifies new, potentially practice-changing data (signals) that might translate into revised practice recommendations. The approach relies on targeted literature searching and the expertise of ASCO guideline panel members to identify signals. For this focused update, a single phase III randomized trial provided the signal.

\section{ASCO}




\section{THE BOTTOM LINE}

\section{Use of Endocrine Therapy for Breast Cancer Risk Reduction: ASCO Clinical Practice Guideline Update Guideline Question}

What is the role of anastrozole in reducing the risk of developing breast cancer in women not previously diagnosed with breast cancer?

\section{Target Population}

Women without a personal history of breast cancer who are at increased risk of developing the disease.

\section{Target Audience}

Medical oncologists, surgical oncologists, gynecologists, primary care physicians, and general practitioners.

\section{Methods}

An Expert Panel was convened to update clinical practice guideline recommendations based on a systematic review of the medical literature.

\section{Updated Recommendations}

Recommendation 4.1. Anastrozole ( $1 \mathrm{mg} /$ day orally for 5 years) should be discussed as an alternative to tamoxifen, raloxifene, or exemestane to reduce the risk of invasive breast cancer in postmenopausal women at increased risk of developing breast cancer.

Recommendation 4.2. Women most likely to benefit from endocrine therapy are those with one of more of the following: a diagnosis of atypical (ductal or lobular) hyperplasia or lobular carcinoma in situ, an estimated 5-year risk (National Cancer Institute Breast Cancer Risk Assessment Tool [BCRAT]) of at least 3\%, a 10-year risk (International Breast Intervention Study [IBIS]/Tyrer-Cuzick Risk Calculator) of at least $5 \%$, or a relative risk of at least four times the population risk for their age group if they are age 40 to 44 years or two times the population risk for their age group if they are age 45 to 69 years.

Recommendation 4.3. Clinicians should not prescribe anastrozole, exemestane, or raloxifene for breast cancer risk reduction in premenopausal women

Recommendation 4.4. Discussions between patients and health care providers should include both the benefits and risks of anastrozole along with the other approved drugs for risk reduction based on menopausal status.

Recommendation 4.5. Prior to initiating an aromatase inhibitor, clinicians should evaluate patients for baseline fracture risk and measure bone mineral density. Multiple studies have reported an increased rate of bone loss in women treated with aromatase inhibitors. Clinicians should use anastrozole with caution in postmenopausal women with moderate bone mineral density loss, and if it is used, they should consider the use of bone-protective agents such as bisphosphonates and receptor activator of nuclear factor kappa-B ligand (RANKL) inhibitors. All patients receiving aromatase inhibitors should be encouraged to exercise regularly and take adequate calcium and vitamin D supplements. A history of osteoporosis and/or severe bone loss is a relative contraindication for the use of anastrozole. In IBIS-II, women with severe osteoporosis (T score $<-4$ or more than two vertebral fractures) were excluded. Other endocrine preventive therapies that do not reduce bone density, such as tamoxifen or raloxifene, are also available for this group of women.

Recommendation 4.6. Clinicians should also inform women of the possibility of joint stiffness, arthralgias, vasomotor symptoms, hypertension, dry eyes, and vaginal dryness while taking anastrozole (Type: evidence based, benefits outweigh harms; Evidence quality: high; Strength of recommendation: strong).

Refer to Table 1 for the full list of recommendations.

\section{ASCO believes that cancer clinical trials are vital to inform medical decisions and improve cancer care, and that all patients should have the opportunity to participate.}

\section{Additional Resources}

More information, including a Data Supplement, slide sets, and clinical tools and resources, is available at www.asco.org/breast-cancer-guidelines. Patient information is available at www.cancer.net. The Methodology Manual, available at www.asco.org/guideline-methodology, provides additional information about the methods used to develop this guideline. 
This systematic review-based guideline product was developed by a multidisciplinary Expert Panel (Appendix Table A1, online only), which included a patient representative and ASCO guidelines staff with health research methodology expertise. The Expert Panel reviewed the evidence and formulated updated recommendations for practice. The Expert Panel conducted a search of the PubMed database to identify randomized controlled trials that addressed the use of pharmacologic interventions for breast cancer risk reduction for the period from September 30, 2011, through November 10, 2018. The disease and intervention search terms were those used for the 2013 guideline update. A separate literature search was conducted to identify relevant clinical practice guidelines, systematic reviews, and meta-analyses.

Additional information about the results of the updated literature search and search strategy strings and results is available at www.asco.org/breast-cancer-guidelines in the Data Supplement (online only). The Data Supplement also includes Quorum diagrams of the updated search and the Clinical Question, as well as a summary of the study quality appraisal. The Methodology Manual (www.asco.org/guidelinemethodology) provides additional information about the methods used to develop this guideline.

The entire Expert Panel contributed to the development of the guideline, provided critical review, and finalized the guideline recommendations. The ASCO Clinical Practice Guidelines Committee reviews and approves all ASCO guidelines. The complete list of recommendations is provided in Table 1, including the updated recommendations. The Expert Panel met via teleconference to consider the evidence identified by the literature search and corresponded through e-mail. The guideline was circulated in draft form to the Expert Panel. All funding for the administration of the project was provided by ASCO.

\section{Guideline Disclaimer}

The clinical practice guidelines and other guidance published herein are provided by the American Society of Clinical Oncology, Inc. ("ASCO") to assist providers in clinical decision making. The information therein should not be relied upon as being complete or accurate, nor should it be considered as inclusive of all proper treatments or methods of care or as a statement of the standard of care. With the rapid development of scientific knowledge, new evidence may emerge between the time information is developed and when it is published or read. The information is not continually updated and may not reflect the most recent evidence. The information addresses only the topics specifically identified therein and is not applicable to other interventions, diseases, or stages of diseases. This information does not mandate any particular course of medical care. Further, the information is not intended to substitute for the independent professional judgment of the treating provider, as the information does not account for individual variation among patients. Recommendations reflect high, moderate, or low confidence that the recommendation reflects the net effect of a given course of action. The use of words like "must," "must not," "should," and "should not" indicate that a course of action is recommended or not recommended for either most or many patients, but there is latitude for the treating physician to select other courses of action in individual cases. In all cases, the selected course of action should be considered by the treating provider in the context of treating the individual patient. Use of the information is voluntary. ASCO provides this information on an "as is" basis, and makes no warranty, express or implied, regarding the information. ASCO specifically disclaims any warranties of merchantability or fitness for a particular use or purpose. ASCO assumes no responsibility for any injury or damage to persons or property arising out of or related to any use of this information or for any errors or omissions.

\section{Guideline and Conflicts of Interest}

The Expert Panel was assembled in accordance with ASCO's Conflict of Interest Policy Implementation for Clinical Practice Guidelines ("Policy," found at http://www.asco.org/rwc). All members of the Expert Panel completed ASCO's disclosure form, which requires disclosure of financial and other interests, including relationships with commercial entities that are reasonably likely to experience direct regulatory or commercial impact as a result of promulgation of the guideline. Categories for disclosure include employment; leadership; stock or other ownership; honoraria, consulting or advisory role; speaker's bureau; research funding; patents, royalties, other intellectual property; expert testimony; travel, accommodations, expenses; and other relationships. In accordance with the Policy, the majority of the members of the Expert Panel did not disclose any relationships constituting a conflict under the Policy.

\section{RESULTS}

The PubMed search, spanning September 2011 to November 2018, which was conducted to identify studies of the use of medications for breast cancer risk reduction, yielded 632 publications. A second PubMed search, spanning September 2011 to February 2019, conducted to identify relevant systematic reviews, meta-analyses, and clinical practice guidelines, yielded 274 records. After the identified abstracts from both searches were reviewed, six full-text articles that included one randomized clinical trial ${ }^{5}$, four systematic reviews and/or meta-analyses, ${ }^{8-11}$ and one clinical practice guideline ${ }^{12}$ were selected for further review by the Expert Panel. Another relevant clinical practice guideline, updated in 2017 by the National Institute for Health and Care Excellence (NICE; https://www.nice. org.uk/guidance/cg164), was identified outside the electronic search by a panel member. Just one publicationthe 2014 report of the IBIS-II randomized, placebocontrolled trial on the use of anastrozole to reduce 
TABLE 1. Summary of All Recommendations

Tamoxifen

1.1. Should be discussed as an option to reduce the risk of invasive $B C$, specifically ER-positive $B C$, in premenopausal women who are $\geq 35$ years of age with a 5 -year projected absolute $\mathrm{BC}$ risk $\geq 1.66 \%$ or with LCIS. Risk reduction benefit continues for at least 10 years.

1.2. Is not recommended for use in women with a history of deep vein thrombosis, pulmonary embolus, stroke, transient ischemic attack, or during prolonged immobilization.

1.3. Is not recommended for women who are pregnant, women who may become pregnant, or nursing mothers.

1.4. Is not recommended in combination with hormone therapy.

1.5. Follow-up should include a timely workup of abnormal vaginal bleeding.

1.6. Discussions with patients and health care providers should include both the risks and benefits of tamoxifen in the preventive setting.

1.7. Dosage: $20 \mathrm{mg} /$ day orally for 5 years.

\section{Raloxifene}

2.1. Should be discussed as an option to reduce the risk of invasive $\mathrm{BC}$, specifically ER-positive BC, in postmenopausal women who are $\geq 35$ years of age with a 5 -year projected absolute $\mathrm{BC}$ risk $\geq 1.66 \%$ or with LCIS.

2.2. May be used longer than 5 years in women with osteoporosis, in whom $\mathrm{BC}$ risk reduction is a secondary benefit.

2.3. Should not be used for BC risk reduction in premenopausal women.

2.4. Is not recommended for use in women with a history of deep vein thrombosis, pulmonary embolus, stroke, or transient ischemic attack, or during prolonged immobilization.

2.5. Discussions with patients and health care providers should include both the risks and benefits of raloxifene in the preventive setting.

2.6. Dosage: $60 \mathrm{mg} /$ day orally for 5 years.

Exemestane

3.1. Should be discussed as an alternative to tamoxifen and/or raloxifene to reduce the risk of invasive $\mathrm{BC}$, specifically ER-positive $\mathrm{BC}$, in postmenopausal women $\geq 35$ years of age with a 5-year projected absolute $\mathrm{BC}$ risk $\geq 1.66 \%$ or with LCIS or atypical hyperplasia.

3.2. Should not be used for BC risk reduction in premenopausal women.

3.3. Discussions with patients and health care providers should include both the risks and benefits of exemestane in the preventive setting
Strong, evidence-based recommendation. Strength of evidence: strong, based on four RCTs with a low risk of bias.
Strong, evidence-based recommendation. Strength of evidence: strong, based on five RCTs with a low risk of bias.

3.4. Dosage: $25 \mathrm{mg} /$ day orally for 5 years. 
Anastrozole

4.1. Anastrozole ( $1 \mathrm{mg} /$ day orally for 5 years) should be discussed as an alternative to tamoxifen, raloxifene, or exemestane to reduce the risk of invasive $\mathrm{BC}$ in postmenopausal women at increased risk of developing BC.

4.2. Women most likely to benefit from endocrine therapy are those with one of more of the following: a diagnosis of atypical (ductal or lobular) hyperplasia or LCIS, an estimated 5-year risk (NCI BCRAT) of at least 3\%, a 10-year risk (IBIS/Tyrer-Cuzick Risk Calculator) of at least $5 \%$, or a relative risk of at least four times the population risk for their age group if their age is 40 to 44 years or two times the population risk for their age group if their age is 45 to 69 years.

4.3. Clinicians should not prescribe anastrozole, exemestane, or raloxifene for $\mathrm{BC}$ risk reduction in premenopausal women.

4.4. Discussions between patients and health care providers should include both the benefits and risks of anastrozole along with the other approved drugs for risk reduction based on menopausal status.

4.5. Prior to initiating an aromatase inhibitor, clinicians should evaluate patients for baseline fracture risk and measure bone mineral density. Multiple studies have reported an increased rate of bone loss in women treated with aromatase inhibitors. Clinicians should use anastrozole with caution in postmenopausal women with moderate bone mineral density loss, and if it is used, they should consider the use of bone-protective agents such as bisphosphonates and RANKL inhibitors. All patients receiving aromatase inhibitors should be encouraged to exercise regularly and take adequate calcium and vitamin D supplements. A history of osteoporosis and/or severe bone loss is a relative contraindication for the use of anastrozole. In IBIS-II, women with severe osteoporosis ( $T$ score $<-4$ or more than two vertebral fractures) were excluded. Other endocrine preventive therapies that do not reduce bone density, such as tamoxifen or raloxifene, are also available for this group of women.

4.6. Clinicians should also inform women of the possibility of joint stiffness, arthralgias, vasomotor symptoms, hypertension, dry eyes, and vaginal dryness while taking anastrozole.
Evidence based, benefits outweigh harms; Evidence quality: high; Strength of recommendation: strong, based on one RCT with low risk of bias.

Abbreviations: BC, breast cancer; BCRAT, Breast Cancer Risk Assessment Tool; ER, estrogen receptor; IBIS, International Breast Intervention Study; LCIS, lobular carcinoma in situ; $\mathrm{NCI}$, National Cancer Institute; RANKL, receptor activator of nuclear factor kappa-B ligand; RCT, randomized controlled trial.

*The "moderate" strength of recommendation here reflects the 2013 system of characterizing the evidence and recommendation strength.

the incidence of breast cancer in postmenopausal women at increased risk of developing breast cancerprovided a signal for substantively revising the guideline recommendations. ${ }^{5}$

\section{CLINICAL QUESTION AND UPDATED RECOMMENDATIONS}

What is the role of anastrozole in reducing the risk of developing breast cancer in women not previously diagnosed with breast cancer?

\section{Recommendation 4.1}

Anastrozole ( $1 \mathrm{mg} /$ day orally for 5 years) should be discussed as an alternative to tamoxifen, raloxifene, or exemestane to reduce the risk of invasive breast cancer in postmenopausal women at increased risk of developing breast cancer.

\section{Recommendation 4.2}

Women most likely to benefit are those with one or more of the following: a diagnosis of atypical (ductal or lobular) hyperplasia or lobular carcinoma in situ, an estimated 5-year risk (National Cancer Institute Breast Cancer Risk Assessment Tool [BCRAT]) of at least 3\%, a 10-year risk (International Breast Intervention Study [IBIS]/Tyrer-Cuzick Risk Calculator) of at least $5 \%$, or a relative risk of at least four times the population risk for their age group if their age is 40 to 44 years or two times that for their age group if their age is 45 to 69 years.

\section{Recommendation 4.3}

Clinicians should not prescribe anastrozole, exemestane, or raloxifene for breast cancer risk reduction in premenopausal women. 


\section{Recommendation 4.4}

Discussions between patients and health care providers should include both the benefits and risks of anastrozole along with the other approved drugs for risk reduction based on menopausal status.

\section{Recommendation 4.5}

Prior to initiating an aromatase inhibitor, clinicians should evaluate patients for baseline fracture risk and measure bone mineral density. Multiple studies have reported an increased rate of bone loss in women treated with aromatase inhibitors. Clinicians should use anastrozole with caution in postmenopausal women with moderate bone mineral density loss, and if it is used, they should consider the use of bone-protective agents such as bisphosphonates and receptor activator of nuclear factor kappa-B ligand (RANKL) inhibitors. All patients receiving aromatase inhibitors should be encouraged to exercise regularly and take adequate calcium and vitamin D supplements. A history of osteoporosis and/or severe bone loss is a relative contraindication for the use of anastrozole. In IBIS-II, women with severe osteoporosis ( $T$ score $<-4$ or more than two vertebral fractures) were excluded. Other endocrine preventive therapies that do not reduce bone density, such as tamoxifen or raloxifene, are also available for this group of women.

\section{Recommendation 4.6}

Clinicians should also inform women of the possibility of joint stiffness, arthralgias, vasomotor symptoms, hypertension, dry eyes, and vaginal dryness while taking anastrozole. (Type: evidence based, benefits outweigh harms; Evidence quality: high; Strength of recommendation: strong).

Literature review and analysis. The literature review conducted for this guideline update identified a single relevant randomized controlled trial that had been published since the 2013 update. Cuzick et $\mathrm{ll}^{5}$ reported on the results of the IBIS-II double-blind, randomized, placebo-controlled trial that assessed the safety and efficacy of the aromatase inhibitor anastrozole ( $1 \mathrm{mg} /$ day orally for 5 years) to reduce the incidence of breast cancer in postmenopausal women at increased risk of developing breast cancer. Table 2 summarizes trial parameters and the eligibility characteristics for the 3,864 postmenopausal women age 40 to 70 years who were randomly assigned. There were no differences in baseline characteristics between the groups. The median age was 59.5 years (interquartile range [IQR], 55-63.5 years), and $18 \%$ of women were older than age 65 years; the median Tyrer-Cuzick model 10-year risk was $7.6 \%$ (IQR, $5.1 \%-10 \%)$.

Table 3 summarizes the results of IBIS-II and the adverse events reported. After a median follow-up of 5 years (IQR, 3.0-7.1 years), intention-to-treat analyses revealed that 85 women in the placebo group (4\%) and 40 women in the anastrozole group (2\%) had developed either breast cancer (hazard ratio [HR], 0.47; 95\% $\mathrm{Cl}, 0.32$ to $0.68 ; P<.001$ ). After 7 years, the predicted cumulative incidence of all breast cancers was twice as high in the placebo group

TABLE 2. Study Characteristics of IBIS-II

\begin{tabular}{|c|c|c|c|c|c|c|c|c|}
\hline $\begin{array}{l}\text { Agent } \\
\text { Category }\end{array}$ & $\begin{array}{l}\text { Interventions/ } \\
\text { Comparisons }\end{array}$ & $\begin{array}{c}\text { Primary } \\
\text { Outcomes }\end{array}$ & Funding & Eligibility Criteria & $\begin{array}{l}\text { No. of Patients } \\
\text { Randomly } \\
\text { Assigned }\end{array}$ & $\begin{array}{c}\text { Accrual } \\
\text { Period }\end{array}$ & $\begin{array}{c}\text { Follow-Up } \\
\text { Period }\end{array}$ & Cohort Characteristics \\
\hline $\begin{array}{r}\text { Aromatase } \\
\text { inhibitor }\end{array}$ & $\begin{array}{l}\text { Anastrozole } \\
1 \mathrm{mg} / \text { day for } \\
5 \text { years } \\
\text { compared } \\
\text { with placebo }\end{array}$ & $\begin{array}{l}\text { Incidence of } \\
\text { invasive and } \\
\text { noninvasive } \\
\text { breast } \\
\text { cancer }\end{array}$ & Public & $\begin{array}{l}\text { Postmenopausal women } \\
\text { age } 40 \text { to70 years with } \\
\text { increased risk of } \\
\text { developing breast } \\
\text { cancer, including } \\
\text { ER-positive DCIS with } \\
\text { unilateral mastectomy } \\
\text { within prior } 6 \text { months, } \\
\text { LCIS, atypical } \\
\text { hyperplasia, or } \\
\text { increased risk by the } \\
\text { Tyrer-Cuzick model of } \\
\text { at least four times the } \\
\text { population risk for } \\
\text { women age } 40 \text { to } 44 \\
\text { years, two times the } \\
\text { population risk for } \\
\text { women age } 45 \text { to } \\
65 \text { years, or } 1.5 \text { times } \\
\text { the population risk for } \\
\text { women age } 60 \text { to } \\
70 \text { years and/or having } \\
\text { a minimum } 10 \text {-year } \\
\text { estimated risk of } 5 \% \text {. }\end{array}$ & $\begin{array}{c}\text { Anastrozole, } \\
\text { 1,920; } \\
\text { placebo, } \\
1,944\end{array}$ & $\begin{array}{c}\text { February } \\
2003 \text { to } \\
\text { January } \\
2012\end{array}$ & 5 years & $\begin{array}{l}\text { Median age, } 59.5 \\
\text { years; median } \\
\text { 10-year risk, } 7.6 \% \text {; } \\
\text { ER-positive DCIS, } \\
\text { 8\%; LCIS/AH, 9\%; } \\
\text { two or more first- } \\
\text { degree relatives with } \\
\text { breast or ovarian } \\
\text { cancer, } 49 \% \text {; } \\
\text { BMI, } 30 \text { kg/m² or } \\
\text { higher than 33\%; } \\
\text { prior hysterectomy, } \\
33 \% \text {; } \\
\text { prior HRT, 47\%; } \\
\text { prior HRT within } \\
12 \text { months, } 8 \% \text {; } \\
\text { currently receiving } \\
\text { bisphosphonate, } \\
16 \%\end{array}$ \\
\hline
\end{tabular}

Abbreviations: AH, atypical hyperplasia; BMI, body mass index; DCIS, ductal carcinoma in situ; ER, estrogen receptor; HRT, hormone replacement therapy; IBIS-II, International Breast Intervention Study II; LCIS, lobular carcinoma in situ. 
TABLE 3. Results of IBIS-II

Variable

No.

$\%$

HR

95\% Cl

RR

95\% Cl

Breast cancer incidence

Sample size

Anastrozole

1,920

Placebo

1,944

All breast cancers

0.47

0.32 to 0.68

$<.001$

Anastrozole

40

Placebo

85

All invasive breast cancers

Anastrozole

0.50

0.32 to 0.76

.001

Placebo

32

64

0.42

0.25 to 0.71

.001

ER-positive

$\begin{array}{ll}20 & 1 \\ 47 & 2\end{array}$

Placebo

0.78

0.35 to 1.72

.538

ER-negative

11

Anastrozole

Placebo

14

All noninvasive breast cancers

LCIS

NR

NR

DCIS

0.30

0.12 to 0.74

.009

Anastrozole

$6<1$

Placebo

20

1

\section{Adverse effects}

Sample size

\begin{tabular}{ll}
\hline Anastrozole & 1,920 \\
\hline Placebo & 1,944 \\
\hline Death &
\end{tabular}

\begin{tabular}{lll}
\hline Anastrozole & 18 & 1 \\
\hline Placebo & 17 & 1
\end{tabular}

Thrombosis or embolism

\begin{tabular}{llll}
\hline Anastrozole & 19 & 1 \\
\hline Placebo & 17 & 1 \\
\hline Deep vein thrombosis & NR & & \\
\hline Pulmonary embolism & NR & & \\
\hline Cardiovascular & NR & & 0.58 \\
\hline Stroke & NR & & 0.39 to 0.85 \\
\hline Transient ischemic attack & NR & & 0.61 \\
\hline Cancers other than breast cancer & & 2 & 0.15 to 2.54 \\
\hline Anastrozole & 40 & 4 & \\
\hline Placebo & 70 & $<1$ & \\
\hline Endometrial cancer & & & \\
\hline Anastrozole & 3 & &
\end{tabular}


TABLE 3. Results of IBIS-II (continued)

\section{Variable}

Fracture

Anastrozole

Placebo

Hypertension

Anastrozole

Placebo

Musculoskeletal

Anastrozole

Placebo

Arthralgia

All

Anastrozole

Placebo

Mild

Anastrozole

Placebo

Moderate

Anastrozole

Placebo

Severe

Anastrozole

Placebo

Joint stiffness

Anastrozole

Placebo

Pain in hand or foot

Anastrozole

Placebo

Carpal tunnel syndrome or nerve compression

Anastrozole

Placebo

Ocular

Anastrozole

Placebo

Cataract

Anastrozole

Placebo

Dry eyes

Anastrozole

Placebo

Vasomotor

Anastrozole

Placebo
No.

$\%$

HR

$95 \% \mathrm{CI}$

$P$

RR

$95 \%$ CI

1.11

0.90 to 1.38

1649

$149 \quad 8$

8

$\begin{array}{ll}89 & 5 \\ 55 & 3\end{array}$

$\begin{array}{ll}1,226 & 64 \\ 1,124 & 58\end{array}$

1.10

1.05 to 1.16

1.10

1.03 to 1.18

1.01

0.89 to 1.15

$\begin{array}{ll}972 & 51 \\ 894 & 46\end{array}$

$385 \quad 20$

1.18

1.04 to 1.33

$\begin{array}{ll}422 & 22 \\ 363 & 19\end{array}$

1.24

0.99 to 1.56

$\begin{array}{ll}151 & 8 \\ 123 & 6\end{array}$

1.51

1.17 to 1.94

$\begin{array}{rr}143 & 7 \\ 96 & 5\end{array}$

1.23

0.99 to 1.51

$\begin{array}{ll}178 & 9 \\ 147 & 8\end{array}$

1.58

1.08 to 2.30

$\begin{array}{ll}67 & 3 \\ 43 & 2\end{array}$

$\begin{array}{ll}348 & 18 \\ 335 & 17\end{array}$

$\begin{array}{ll}90 & 5 \\ 95 & 5\end{array}$

$\begin{array}{ll}83 & 4 \\ 58 & 2\end{array}$

$\begin{array}{rr} & \\ 1,090 & 57 \\ 961 & 49\end{array}$

(continued on following page)
1.0

0.92 to 1.21

\begin{tabular}{lll} 
& 1.45 & 1.04 to 2.01 \\
\hline 4 & & \\
\hline 57 & 1.15 & 1.08 to 1.22 \\
\hline 49 & & \\
\hline (continued on following page) & & \\
\hline
\end{tabular}


TABLE 3. Results of IBIS-II (continued)

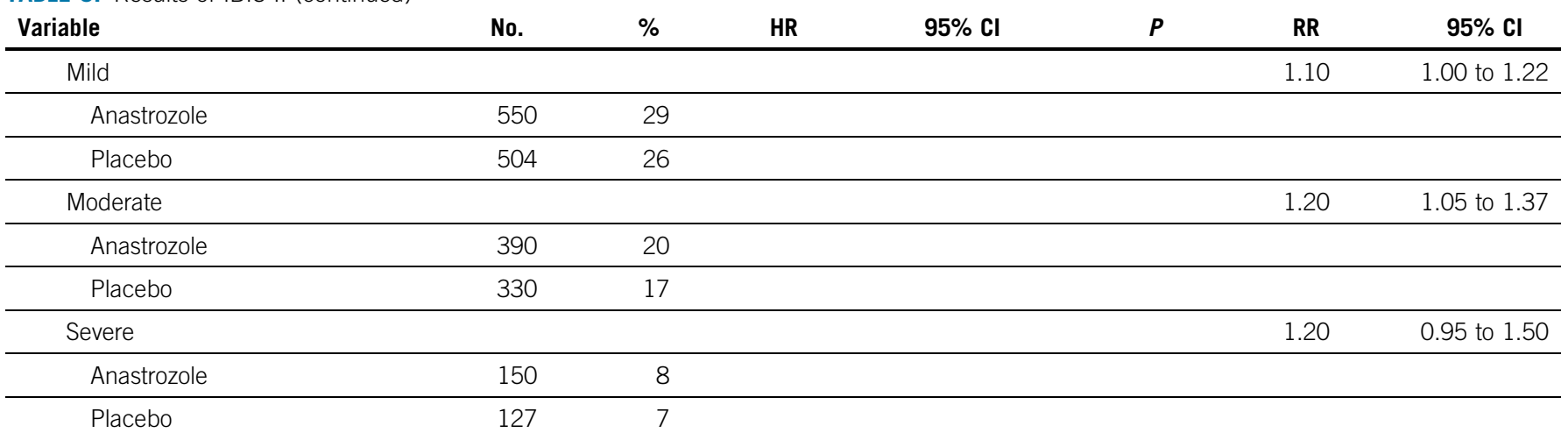

NOTE. Median follow-up, 5 years (range, 3.0 to 7.1 years).

Abbreviations: DCIS, ductal carcinoma in situ; ER, estrogen receptor; HR, hazard ratio; IBIS-II, International Breast Intervention Study II; LCIS, lobular carcinoma in situ; NR, not reported; RR, risk ratio.

(5.6\%) versus the anastrozole group (2.8\%). Five-year adherence was estimated to be less in the anastrozole group compared with the placebo group $(68 \%$ v $72 \%)$. In multivariable analyses, women randomly assigned to anastrozole and reporting gynecologic symptoms at 6 months were less likely to be adherent at 4.5 years compared with those not reporting these symptoms $(\mathrm{HR}, 0.69 ; 95 \% \mathrm{Cl}$, 0.55 to 0.88$).{ }^{13}$

In subgroup analyses, the reduction in breast cancer risk for invasive cancer was limited to estrogen receptorpositive and/or progesterone receptor-positive tumors (HR, $0.42 ; 95 \% \mathrm{Cl}, 0.25$ to $0.71 ; P=.001)$. Furthermore, there appeared to be little difference in risk reduction by age $<60$ years or $>60$ years or body mass index. There was a clear risk reduction for women with no prior hormone replacement therapy, but not for women with prior hormone replacement therapy. The investigators reported 35 deaths by the data cutoff: 17 deaths in the placebo group and 18 deaths in the anastrozole group. However, no specific causes were more common in one group than in the other group ( $P=.836)$. With respect to adverse events, vasomotor symptoms (hot flashes, night sweats) and musculoskeletal symptoms (carpal tunnel syndrome, joint stiffness, moderate arthralgia) were significantly increased with anastrozole. The investigators also reported an increase in frequency of hypertension with anastrozole as well as a greater frequency of dry eyes.

Similar to that for tamoxifen, raloxifene, and exemestane, there is no evidence for a survival advantage for anastrozole given for primary prevention as opposed to breast cancer treatment. It is unclear that we will ever have the ability to detect survival effects due to low numbers of breast cancer events, limited statistical power, and use of preventive agents by women in the placebo group after trial conclusion. However, a reduction in incidence itself is an important end point. Of note, there are no data on the use of anastrozole for breast cancer risk reduction in women with germ line breast cancer predisposition mutations or in men with breast cancer.

\section{CLINICAL CONSIDERATIONS FOR USE OF ENDOCRINE PREVENTION PHARMACEUTICAL AGENTS FOR BREAST CANCER RISK REDUCTION}

In this section, the Expert Panel provides practical answers to questions frequently raised by patients and/or providers regarding the use of tamoxifen, raloxifene, or an aromatase inhibitor for breast cancer risk reduction based on the best available data. The Expert Panel also summarizes evidence from a recently reported trial of low-dose tamoxifen as an alternative to standard-dose tamoxifen for breast cancer risk reduction in women with intraepithelial neoplasia. ${ }^{6}$

\section{Risk Threshold for Considering Endocrine Therapy for Primary Breast Cancer Prevention}

There is no single absolute or relative risk threshold for which endocrine therapy should be considered for breast cancer risk reduction. The US Preventive Services Task Force ${ }^{14}$ recommends a 5 -year risk of at least 3\% (based on the National Cancer Institute Breast Cancer Risk Assessment Tool [BCRAT]), and NICE recommends an agedependent, 10-year risk of $\geq 5 \% .{ }^{15}$ Of note, although the eligibility for the Breast Cancer Prevention Trial (P-1) of the National Surgical Adjuvant Breast and Bowel Project trial and the Study of Tamoxifen and Raloxifene (STAR) for the Prevention of Breast Cancer in Postmenopausal Women trial was a 5 -year BCRAT of $1.66 \%$, the mean risk among trial entrants was actually higher than that; the mean 5-year breast cancer risk in the STAR trial, for instance, was $4.03 \%$ (standard deviation, $2.17 \%$ ). The two models most frequently used to calculate breast cancer risk in the phase III prevention trials and in clinical practice today are the BCRAT model (https://bcrisktool.cancer.gov.) and the IBIS/Tyrer-Cuzick model (http://www.ems-trials. 
org/riskevaluator/). The BCRAT model provides absolute 5-year and lifetime risks while the Tyrer-Cuzick model provides 10-year and residual absolute lifetime risk estimates. ${ }^{16-18}$ In Version 8 of the Tyrer-Cuzick model, a 5-year risk can also be estimated. Because the BCRAT model does not consider age at onset of cancer in family members or cancer in second-degree relatives, the Tyrer-Cuzick model is more appropriate when these features are present in families. The Expert Panel provides more details on risk models in the Appendix (online only).

Women with atypical hyperplasia (AH) or lobular carcinoma in situ (LCIS) have a four- to 10-fold increase in breast cancer risk compared with those without a precursor lesion or a 5 -year risk of 3\% to $5 \%$ and a 10 -year risk of $5 \%$ to $10 \% .{ }^{19-21}$ Given the magnitude of risk for $\mathrm{AH}$ and $\mathrm{LCIS}$ and the large risk reduction observed with tamoxifen and anastrozole in the NSABP P-1 and IBIS-II trials, respectively, all women with $\mathrm{AH}$ or LCIS who are age 35 years or older, have completed childbearing, and who have no medical contraindications should be offered endocrine therapy. ${ }^{5,22}$ This also applies to women of African descent, whose risk for breast cancer is increased to an equal degree by atypical lesions, even though their estimated risk using the BCRAT model may be lower than the thresholds discussed earlier in the text. ${ }^{23-25}$

Women age 35 to 59 years with a calculated 5 -year risk of $\geq 3 \%$ or with a 10 -year absolute risk of $\geq 5 \%$ (based on the BCRAT and IBIS models, respectively) should also have the option of endocrine risk reduction. Women with a calculated 5 -year risk of $\geq 3 \%$ who are age 35 to 39 years will have a six- to 10 -fold increase in risk; those age 40 to 44 years will have a four-fold increase in risk; and those age 45 to 59 years will have a two-fold increase in risk compared with the average population risk of women in the same age groups. For women age 60 to 69 years with a 5 -year absolute risk of $3 \%$, the risks versus benefits are less clear because the relative risk is only 1.5 - to 1.8 -fold greater than the average population risk, and the risk of serious adverse effects is higher than that in younger women. 5,22,26,27

Examples of clinical situations that should alert providers to consider endocrine risk reduction therapy include (1) an affected first-degree relative with breast cancer diagnosed before age 45 years, two affected first-degree relatives at any age, or an affected first-degree and an affected seconddegree relative; (2) inheritance of a moderate- or highpenetrance gene mutation for breast cancer susceptibility; or (3) receipt of chest wall radiation at age $<30$ years. ${ }^{28-34}$ At present, high breast density alone is not an indication for endocrine prevention therapy, and it is not considered by all risk assessment models. At present, some risk models, such as Version 8.0 of the IBIS/Tyrer-Cuzick model, incorporate breast density as a risk factor, but BCRAT does not.
Regardless of risk level, all women should be encouraged to practice healthy behaviors. This includes at least 150 minutes of moderate-intensity or 75 minutes of vigorous-intensity exercise per week, maintaining a healthy weight (ie, body mass index between 18.5 and $24.9 \mathrm{~kg} / \mathrm{m}^{2}$ ), and limiting alcohol consumption to $<7$ drinks per week (https://www.cancer.org/cancer/breast-cancer.html, http:// www.aicr.org, https://www.nhlbi.nih.gov/health/educational/ lose_wt/risk.htm). In observational studies, healthy behaviors have been associated with at least a $20 \%$ to $30 \%$ reduction in breast cancer incidence irrespective of risk level. ${ }^{35-39}$

\section{Low-Dose $(5 \mathrm{mg}$ ) Versus Standard-Dose Tamoxifen}

A recent randomized trial in women with intraepithelial neoplasia suggests that low-dose tamoxifen reduces risk of breast cancer relative to placebo, but there are no data on equivalence of the two dosages. DeCensi et $\mathrm{al}^{6}$ recently reported results of a trial in $\mathbf{5 0 0}$ women with intraepithelial neoplasia (atypical hyperplasia, lobular carcinoma, or ductal carcinoma in situ [DCIS]) who were randomly assigned to tamoxifen at one quarter of the standard $20 \mathrm{mg}$ dose ( $5 \mathrm{mg} /$ day) or placebo for 3 years. At a median followup of 5 years, those randomly assigned to low-dose tamoxifen had half the neoplastic breast events (DCIS or invasive cancer) as those randomly assigned to placebo. By comparison, in the NSABP P-1 trial, the relative reduction in invasive cancer for full-dose tamoxifen compared with placebo was $49 \%$ overall: $86 \%$ for women with a prior biopsy of $\mathrm{AH}$ and $59 \%$ for those with LCIS. Noninvasive cancer was also reduced by half. ${ }^{22}$ The reasons for the higher proportional risk reduction for women with $\mathrm{AH}$ and LCIS are not entirely clear but may, in part, be related to the combination of higher estrogen receptor density and proliferation in $\mathrm{AH}$ and LCIS than in normal breast tissue. ${ }^{40,41}$ Results of low-dose tamoxifen are consistent with the effect of $20 \mathrm{mg} /$ day of the NSABP-B24 (A Clinical Trial to Evaluate the Worth of Tamoxifen in Conjunction with Lumpectomy and Breast Irradiation for the Treatment of Noninvasive Intraductal Carcinoma [DCIS] of the Breast) subgroup analysis of hormone-sensitive DCIS, in which the HR was $0.58(95 \% \mathrm{Cl}, 0.42$ to 0.81$) .{ }^{42}$ Low-dose tamoxifen compared with placebo was not associated with an increase in the number of serious adverse effects, including deep venous thrombosis and endometrial cancer. The incidence of hot flashes was slightly higher than with placebo, although trial adherence was similar. Because concern about adverse effects is a major reason for poor uptake of endocrine therapy for breast cancer risk reduction, ${ }^{4,43-45}$ low-dose tamoxifen may be an alternative in women with intraepithelial neoplasia.

\section{Upper Age Limit for Endocrine Risk Reduction Therapy}

Women age 70 years or older should not be offered endocrine prevention unless their short-term risk is in the range of $1 \%$ or more per year (eg, atypical hyperplasia plus family history or LCIS), they are active, and they have a life 
TABLE 4. Adverse Effects of Endocrine Therapy

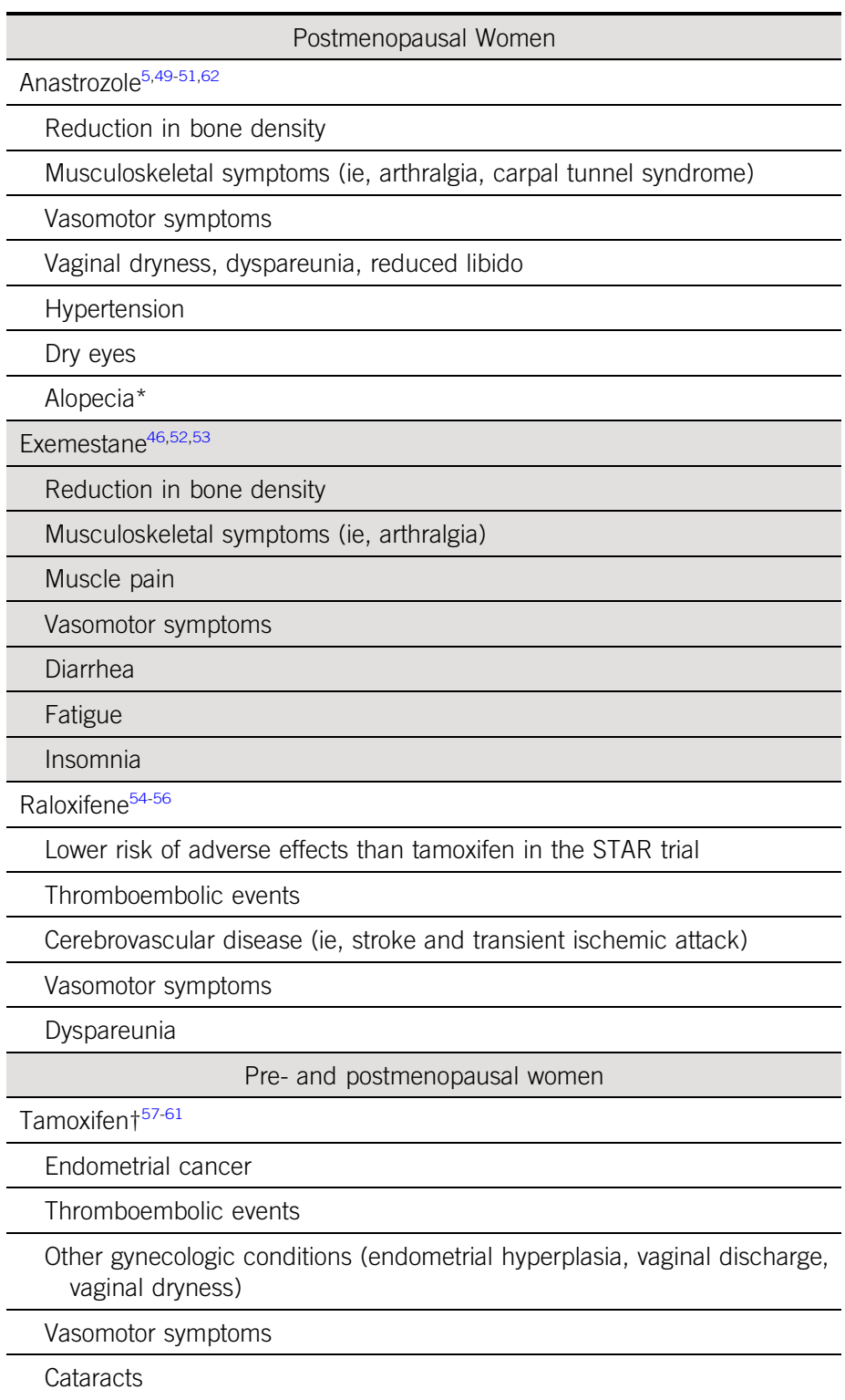

Abbreviation: STAR, Study of Tamoxifen and Raloxifene (STAR) for the Prevention of Breast Cancer in Postmenopausal Women.

${ }^{*}$ Alopecia is likely an underreported adverse effect in clinical trials.

†The incidence for single-agent aromatase inhibitors and selective estrogen receptor modulators seems to be similar at $3 \%$ to $4 \%$.

expectancy of 10 or more years. Risk benefit will vary by age, medical circumstances, and the prevention drug. ${ }^{27}$

\section{Longer Duration of Endocrine Therapy for Breast Cancer Risk Reduction}

While the standard duration is 5 years, women who stop endocrine therapy after 3 years for a variety of reasons will likely still derive a benefit. This conclusion is based on the $50 \%$ risk reduction observed in the DeCensi et al trial of
3 years of low-dose tamoxifen versus placebo ${ }^{6}$ and on the $65 \%$ risk reduction reported in the MAP3 (Exemestane in Preventing Cancer in Postmenopausal Women at Increased Risk of Developing Breast Cancer) trial after a median of 3 years of exemestane. ${ }^{46}$

Currently, raloxifene, which is frequently prescribed to postmenopausal women for osteoporosis prevention, is the only drug with clinical trial experience of more than 5 years of use for breast cancer risk reduction. ${ }^{47}$ There are no data from randomized trials for tamoxifen, exemestane, or anastrozole to be given for longer than 5 years for women without a prior diagnosis of cancer; therefore, this practice is not advised. Furthermore, in adjuvant cancer treatment trials comparing 10 years versus 5 years of treatment, tamoxifen was associated with an increase in the risk of uterine cancer and pulmonary embolism and exemestane with an increase in the risk of osteoporosis, fracture, and hypertension. ${ }^{46,48}$

\section{Deciding Between an Aromatase Inhibitor and a Selective Estrogen Receptor Modulator for Endocrine Prevention Therapy in Postmenopausal Women}

Decisions about the use of aromatase inhibitors versus selective estrogen receptor modulators are usually made based on age, symptoms, and comorbidities, given that the aromatase inhibitors (exemestane and anastrozole) and the selective estrogen receptor modulators (tamoxifen and raloxifene) both reduce breast cancer incidence compared with placebo. There is no primary prevention trial comparing tamoxifen to the aromatase inhibitors. ${ }^{26}$ In women with DCIS, there was no difference in breast cancer incidence in a randomized trial of tamoxifen versus anastrozole. However, as expected, the adverse effect profiles for the two agents differed. There was a higher incidence of osteoporosis, fractures, joint stiffness, carpal tunnel syndrome, hypercholesterolemia, stroke, and vaginal dryness with anastrozole versus tamoxifen, but there was a higher incidence of deep venous thrombosis, pulmonary emboli, and vaginal discharge with tamoxifen than with anastrozole. Table 4 lists adverse effects of endocrine therapy for each of the agents studied. About half the women in both groups had vasomotor symptoms, and these symptoms were slightly more frequent with tamoxifen. ${ }^{62}$

Providers should have a higher threshold for prescribing aromatase inhibitors in women without breast cancer that may exacerbate underlying medical problems such as moderate to severe bone mineral density loss and poorly controlled hypertension. Tamoxifen or raloxifene is likely a better choice than aromatase inhibitors in women with osteoporosis. By contrast, tamoxifen and raloxifene are contraindicated in women with prior history of deep venous thrombosis or pulmonary embolism, and an aromatase inhibitor would a better choice under these circumstances. At least for tamoxifen, a predisposition to 
deep vein thrombosis seems to be related primarily to obesity, immobility, and recent surgery. ${ }^{63,64}$ Tamoxifen, rather than anastrozole, exemestane, or raloxifene, may also be a better option in a woman who suffers from vaginal dryness. Finally, because tamoxifen is also associated with increased risk of endometrial cancer and cataracts in older women, the benefit-to-risk ratio in women older than age 60 years with a uterus and normal bone density is likely to be greater for aromatase inhibitors than tamoxifen.

\section{ADDITIONAL RESOURCES}

Additional information, including data supplements, evidence tables, and clinical tools and resources, can be found at www.asco.org/breast-cancer-guidelines. Patient information is available there and at www. cancer.net.

\section{AFFILIATIONS}

${ }^{1}$ Johns Hopkins School of Medicine and Johns Hopkins Bloomberg School of Public Health, Baltimore, MD

${ }^{2}$ University of Kansas Medical Center, Kansas City, KS

${ }^{3}$ Johns Hopkins School of Medicine, Baltimore, MD

${ }^{4}$ University of Texas MD Anderson Cancer Center, Houston, TX

${ }^{5}$ University of Washington, Seattle, WA

${ }^{6}$ National Hospital E.O. Ospedali Galliera S.C. Oncologia Medica, Genoa, Italy; and Queen Mary University of London, United Kingdom

${ }^{7}$ Cancer Care Specialists of Illinois, Swansea, IL

${ }^{8}$ Dana-Farber Cancer Institute, Boston, MA

${ }^{9}$ Yale Cancer Center, New Haven, CT

${ }^{10}$ Northwestern University Feinberg School of Medicine, Chicago, IL

${ }^{11}$ University of Basel Nursing Science, Basel, Switzerland

${ }^{12}$ Mayo Clinic Cancer Center, Rochester, MN

${ }^{13}$ Cancer Care of Western North Carolina, Asheville, NC

${ }^{14}$ Florida International University, Miami, FL

${ }^{15}$ American Society of Clinical Oncology, Alexandria, VA

\section{CORRESPONDING AUTHOR}

American Society of Clinical Oncology, 2318 Mill Rd, Suite 800, Alexandria, VA 22314; e-mail: guidelines@asco.org.

Editor's note: This American Society of Clinical Oncology Clinical Practice Guideline provides recommendations, with comprehensive review and analyses of the relevant literature for each recommendation. More information, including a Data Supplement, additional evidence

\section{RELATED ASCO GUIDELINES}

- Fertility Preservation in Patients With Cancer (http://ascopubs.org/doi/10.1200/JC0.2018. 78.1914)

- Interventions to Address Sexual Problems in People With Cancer (http://ascopubs.org/doi/ 10.1200/JCO.2017.75.8995)

- Prevention and Monitoring of Cardiac Dysfunction in Survivors of Adult Cancers (https://ascopubs.org/ doi/10.1200/JC0.2016.70.5400)

- ACS/ASCO Breast Cancer Survivorship Care Guideline (http://ascopubs.org/doi/10.1200/ JC0.2015.64.3809) tables, slide sets, clinical tools and resources, and links to patient information at www.cancer.net, is available at www.asco.org/ breast-cancer-guidelines.

\section{AUTHORS' DISCLOSURES OF POTENTIAL CONFLICTS OF INTEREST} AND DATA AVAILABILITY STATEMENT

Disclosures provided by the authors and data availability statement (if applicable) are available with this article at DOI https://doi.org/10.1200/ JCO.19.01472

\section{AUTHOR CONTRIBUTIONS}

Conception and design: All authors

Collection and assembly of data: Kala Visvanathan, Carol J. Fabian, Mark R. Somerfield

Data analysis and interpretation: All authors

Manuscript writing: All authors

Final approval of manuscript: All authors

Accountable for all aspects of the work: All authors

\section{ACKNOWLEDGMENT}

The Expert Panel thanks Zoneddy Dayao, Charles Schapiro, and the Clinical Practice Guidelines Committee for their thoughtful reviews and insightful comments on this guideline and Brittany E. Harvey and Shannon E. McKernin for assistance with construction of evidence summary tables,

\section{REFERENCES}

1. Chlebowski RT, Collyar DE, Somerfield MR, et al: American Society of Clinical Oncology technology assessment on breast cancer risk reduction strategies: Tamoxifen and raloxifene. J Clin Oncol 17:1939-1955, 1999

2. Chlebowski RT, Col N, Winer EP, et al: American Society of Clinical Oncology technology assessment of pharmacologic interventions for breast cancer risk reduction including tamoxifen, raloxifene, and aromatase inhibition. J Clin Oncol 20:3328-3343, 2002

3. Visvanathan K, Chlebowski RT, Hurley P, et al: American Society of Clinical Oncology clinical practice guideline update on the use of pharmacologic interventions including tamoxifen, raloxifene, and aromatase inhibition for breast cancer risk reduction. J Clin Oncol 27:3235-3258, 2009

4. Visvanathan K, Hurley P, Bantug E, et al: Use of pharmacologic interventions for breast cancer risk reduction: American Society of Clinical Oncology clinical practice guideline. J Clin Oncol 31:2942-2962, 2013

5. Cuzick J, Sestak I, Forbes JF, et al: Anastrozole for prevention of breast cancer in high-risk postmenopausal women (IBIS-II): An international, double-blind, randomised placebo-controlled trial. Lancet 383:1041-1048, 2014

6. DeCensi A, Puntoni M, Guerrieri-Gonzaga A, et al: Randomized placebo controlled trial of low-dose tamoxifen to prevent local and contralateral recurrence in breast intraepithelial neoplasia. J Clin Oncol 37:1629-1637, 2019 
7. Shojania KG, Sampson M, Ansari MT, et al: How quickly do systematic reviews go out of date? A survival analysis. Ann Intern Med 147:224-233, 2007

8. Mocellin S, Pilati P, Briarava M, et al: Breast cancer chemoprevention: A network meta-analysis of randomized controlled trials. J Natl Cancer Inst 108, 2015

9. Pruthi S, Heisey RE, Bevers TB: Chemoprevention for breast cancer. Ann Surg Oncol 22:3230-3235, 2015

10. Nelson HD, Smith ME, Griffin JC, et al: Use of medications to reduce risk for primary breast cancer: A systematic review for the U.S. Preventive Services Task Force. Ann Intern Med 158:604-614, 2013

11. Olin JL, St Pierre M: Aromatase inhibitors in breast cancer prevention. Ann Pharmacother 48:1605-1610, 2014

12. Moyer VA, U.S. Preventive Services Task Force: Medications to decrease the risk for breast cancer in women: Recommendations from the U.S. Preventive Services Task Force recommendation statement. Ann Intern Med 159:698-708, 2013

13. Sestak I, Smith SG, Howell A, et al: Early participant-reported symptoms as predictors of adherence to anastrozole in the International Breast Cancer Intervention Studies II. Ann Oncol 29:504-509, 2018

14. Nelson HD, Smith ME, Griffin JC, et al: Use of medications to reduce risk for primary breast cancer: A systematic review for the U.S. Preventive Services Task Force. Ann Intern Med 158:604-614, 2013

15. Evans DG, Howell SJ, Howell A: Personalized prevention in high risk individuals: Managing hormones and beyond. Breast 39:139-147, 2018

16. Tyrer J, Duffy SW, Cuzick J: A breast cancer prediction model incorporating familial and personal risk factors. Stat Med 23:1111-1130, 2004

17. Brentnall AR, Cuzick J, Buist DSM, et al: Long-term accuracy of breast cancer risk assessment combining classic risk factors and breast density. JAMA Oncol 4: e180174, 2018

18. Coopey SB, Acar A, Griffin M, et al: The impact of patient age on breast cancer risk prediction models. Breast J 24:592-598, 2018

19. Hartmann LC, Sellers TA, Frost MH, et al: Benign breast disease and the risk of breast cancer. N Engl J Med 353:229-237, 2005

20. Degnim AC, Dupont WD, Radisky DC, et al: Extent of atypical hyperplasia stratifies breast cancer risk in 2 independent cohorts of women. Cancer 122: 2971-2978, 2016

21. Coopey SB, Mazzola E, Buckley JM, et al: The role of chemoprevention in modifying the risk of breast cancer in women with atypical breast lesions. Breast Cancer Res Treat 136:627-633, 2012

22. Fisher B, Costantino JP, Wickerham DL, et al: Tamoxifen for prevention of breast cancer: Report of the National Surgical Adjuvant Breast and Bowel Project P-1 Study. J Natl Cancer Inst 90:1371-1388, 1998

23. Newman LA, Stark A, Chitale D, et al: Association between benign breast disease in African American and white American women and subsequent triplenegative breast cancer. JAMA Oncol 3:1102-1106, 2017

24. Worsham MJ, Raju U, Lu M, et al: Multiplicity of benign breast lesions is a risk factor for progression to breast cancer. Clin Cancer Res 13:5474-5479, 2007

25. Worsham MJ, Abrams J, Raju U, et al: Breast cancer incidence in a cohort of women with benign breast disease from a multiethnic, primary health care population. Breast J 13:115-121, 2007

26. Vogel VG, Costantino JP, Wickerham DL, et al: Update of the National Surgical Adjuvant Breast and Bowel Project Study of Tamoxifen and Raloxifene (STAR) P-2 Trial: Preventing breast cancer. Cancer Prev Res (Phila) 3:696-706, 2010

27. Freedman AN, Yu B, Gail MH, et al: Benefit/risk assessment for breast cancer chemoprevention with raloxifene or tamoxifen for women age 50 years or older. J Clin Oncol 29:2327-2333, 2011

28. Brewer HR, Jones ME, Schoemaker MJ, et al: Family history and risk of breast cancer: An analysis accounting for family structure. Breast Cancer Res Treat 165: 193-200, 2017

29. Ahern TP, Sprague BL, Bissell MCS, et al: Family history of breast cancer, breast density, and breast cancer risk in a U.S. breast cancer screening population. Cancer Epidemiol Biomarkers Prev 26:938-944, 2017

30. Tung N, Domchek SM, Stadler Z, et al: Counselling framework for moderate-penetrance cancer-susceptibility mutations. Nat Rev Clin Oncol 13:581-588, 2016

31. Dupont WD, Page DL: Risk factors for breast cancer in women with proliferative breast disease. N Engl J Med 312:146-151, 1985

32. Ward EM, DeSantis CE, Lin CC, et al: Cancer statistics: Breast cancer in situ. CA Cancer J Clin 65:481-495, 2015

33. Henderson TO, Amsterdam A, Bhatia S, et al: Systematic review: Surveillance for breast cancer in women treated with chest radiation for childhood, adolescent, or young adult cancer. Ann Intern Med 152:W144-W154, 2010

34. Easton DF, Pharoah PD, Antoniou AC, et al: Gene-panel sequencing and the prediction of breast-cancer risk. N Engl J Med 372:2243-2257, 2015

35. Maas $\mathrm{P}$, Barrdahl $\mathrm{M}$, Joshi AD, et al: Breast cancer risk from modifiable and nonmodifiable risk factors among white women in the United States. JAMA Oncol 2: 1295-1302, 2016

36. Pijpe A, Manders P, Brohet RM, et al: Physical activity and the risk of breast cancer in BRCA1/2 mutation carriers. Breast Cancer Res Treat 120:235-244, 2010

37. Song M, Giovannucci E: Preventable incidence and mortality of carcinoma associated with lifestyle factors among white adults in the United States. JAMA Oncol 2:1154-1161, 2016

38. Kotsopoulos J, Olopado OI, Ghadirian P, et al: Changes in body weight and the risk of breast cancer in BRCA1 and BRCA2 mutation carriers. Breast Cancer Res 7:R833-R843, 2005

39. Lammert J, Lubinski J, Gronwald J, et al: Physical activity during adolescence and young adulthood and the risk of breast cancer in BRCA1 and BRCA2 mutation carriers. Breast Cancer Res Treat 169:561-571, 2018

40. Allred DC, Mohsin SK: Biological features of premalignant disease in the human breast. J Mammary Gland Biol Neoplasia 5:351-364, 2000

41. Martinez AP, Cohen C, Hanley KZ, et al: Estrogen receptor and cytokeratin 5 are reliable markers to separate usual ductal hyperplasia from atypical ductal hyperplasia and low-grade ductal carcinoma in situ. Arch Pathol Lab Med 140:686-689, 2016

42. Allred DC, Anderson SJ, Paik S, et al: Adjuvant tamoxifen reduces subsequent breast cancer in women with estrogen receptor-positive ductal carcinoma in situ: A study based on NSABP protocol B-24. J Clin Oncol 30:1268-1273, 2012

43. Bambhroliya A, Chavez-MacGregor M, Brewster AM: Barriers to the use of breast cancer risk reduction therapies. J Natl Compr Canc Netw 13:927-935, 2015

44. Kaplan CP, Haas JS, Pérez-Stable EJ, et al: Breast cancer risk reduction options: Awareness, discussion, and use among women from four ethnic groups. Cancer Epidemiol Biomarkers Prev 15:162-166, 2006

45. Ropka ME, Keim J, Philbrick JT: Patient decisions about breast cancer chemoprevention: A systematic review and meta-analysis. J Clin Oncol 28:3090-3095, 2010

46. Goss PE, Ingle JN, Alés-Martínez JE, et al: Exemestane for breast-cancer prevention in postmenopausal women. N Engl J Med 364:2381-2391, 2011

47. Martino S, Cauley JA, Barrett-Connor E, et al: Continuing outcomes relevant to Evista: Breast cancer incidence in postmenopausal osteoporotic women in a randomized trial of raloxifene. J Natl Cancer Inst 96:1751-1761, 2004

48. Goss PE, Ingle JN, Pritchard KI, et al: Extending aromatase-inhibitor adjuvant therapy to 10 years. N Engl J Med 375:209-219, 2016 
49. Sestak I, Singh S, Cuzick J, et al: Changes in bone mineral density at 3 years in postmenopausal women receiving anastrozole and risedronate in the IBIS-II bone substudy: An international, double-blind, randomised, placebo-controlled trial. Lancet Oncol 15:1460-1468, 2014

50. Cella D, Fallowfield L, Barker P, et al: Quality of life of postmenopausal women in the ATAC ("Arimidex", tamoxifen, alone or in combination) trial after completion of 5 years' adjuvant treatment for early breast cancer. Breast Cancer Res Treat 100:273-284, 2006

51. Freites-Martinez A, Shapiro J, Chan D, et al: Endocrine therapy-induced alopecia in patients with breast cancer. JAMA Dermatol 154:670-675, 2018

52. Cheung AM, Tile L, Cardew S, et al: Bone density and structure in healthy postmenopausal women treated with exemestane for the primary prevention of breast cancer: A nested substudy of the MAP.3 randomised controlled trial. Lancet Oncol 13:275-284, 2012

53. Maunsell E, Goss PE, Chlebowski RT, et al: Quality of life in MAP.3 (mammary prevention 3): A randomized, placebo-controlled trial evaluating exemestane for prevention of breast cancer. J Clin Oncol 32:1427-1436, 2014

54. Land SR, Wickerham DL, Costantino JP, et al: Patient-reported symptoms and quality of life during treatment with tamoxifen or raloxifene for breast cancer prevention: The NSABP Study of Tamoxifen and Raloxifene (STAR) P-2 trial. JAMA 295:2742-2751, 2006

55. Vogel VG, Costantino JP, Wickerham DL, et al: Effects of tamoxifen vs raloxifene on the risk of developing invasive breast cancer and other disease outcomes: The NSABP Study of Tamoxifen and Raloxifene (STAR) P-2 trial. JAMA 295:2727-2741, 2006

56. Messalli EM, Scaffa C: Long-term safety and efficacy of raloxifene in the prevention and treatment of postmenopausal osteoporosis: An update. Int J Womens Health 1:11-20, 2010

57. Cuzick J, Forbes JF, Sestak I, et al: Long-term results of tamoxifen prophylaxis for breast cancer: 96-month follow-up of the randomized IBIS-I trial. J Natl Cancer Inst 99:272-282, 2007

58. Cuzick J, Sestak I, Cawthorn S, et al: Tamoxifen for prevention of breast cancer: Extended long-term follow-up of the IBIS-I breast cancer prevention trial. Lancet Oncol 16:67-75, 2015

59. Smith SG, Sestak I, Howell A, et al: Participant-reported symptoms and their effect on long-term adherence in the International Breast Cancer Intervention Study I (IBIS I). J Clin Oncol 35:2666-2673, 2017

60. Cella D, Land SR, Chang CH, et al: Symptom measurement in the Breast Cancer Prevention Trial (BCPT) (P-1): Psychometric properties of a new measure of symptoms for midlife women. Breast Cancer Res Treat 109:515-526, 2008

61. Saggar V, Wu S, Dickler MN, et al: Alopecia with endocrine therapies in patients with cancer. Oncologist 18:1126-1134, 2013

62. Forbes JF, Sestak I, Howell A, et al: Anastrozole versus tamoxifen for the prevention of locoregional and contralateral breast cancer in postmenopausal women with locally excised ductal carcinoma in situ (IBIS-II DCIS): A double-blind, randomised controlled trial. Lancet 387:866-873, 2016

63. Abramson N, Costantino JP, Garber JE, et al: Effect of factor V Leiden and prothrombin G20210-->A mutations on thromboembolic risk in the national surgical adjuvant breast and bowel project breast cancer prevention trial. J Natl Cancer Inst 98:904-910, 2006

64. Duggan C, Marriott K, Edwards R, et al: Inherited and acquired risk factors for venous thromboembolic disease among women taking tamoxifen to prevent breast cancer. J Clin Oncol 21:3588-3593, 2003

\section{Participate in ASCO's Practice Guidelines Implementation Network and Influence Cancer Care}

ASCO members are invited to serve in the society's Practice Guidelines Implementation Network (PGIN), a network of oncology professionals who raise awareness of ASCO's evidence-based recommendations on cancer care.

Participation in PGIN provides an opportunity for members to positively influence the way that clinical oncology is delivered now and in the future. PGIN members have the opportunity to:

- Participate in guideline panels and advisory groups

- Aid in developing and reviewing guidelines and guideline clinical tools and resources

- Serve as an "ambassador" to state societies

- Better implement guidelines

To learn how you can participate, visit asco.org/guidelines, or contact pgin@asco.org 


\section{Use of Endocrine Therapy for Breast Cancer Risk Reduction: ASCO Clinical Practice Guideline Update}

The following represents disclosure information provided by authors of this manuscript. All relationships are considered compensated. Relationships are self-held unless noted. I = Immediate Family Member, Inst = My Institution. Relationships may not relate to the subject matter of this manuscript. For more information about ASCO's conflict of interest policy, please refer to www.asco.org/rwc or ascopubs.org/jco/site/ifc.

Kala Visvanathan

Patents, Royalties, Other Intellectual Property: Licensing of patent with Cepheid (Inst)

Carol J. Fabian

Research Funding: DSM (Inst), Pfizer (Inst)

\section{Elissa Bantug}

Consulting or Advisory Role: Solace

Andrea DeCensi

Research Funding: E.O. Ospedali Galliera (Inst)

Justin Floyd

Stock and Other Ownership Interests: Seattle Genetics, Celldex, Geron

Judy E. Garber

Consulting or Advisory Role: Novartis (I), GTx (I), Helix BioPharma, Konica Minolta, Aleta BioTherapeutics (I), H3 Biomedicine (I), Kronos Bio (I)

Research Funding: Novartis (I), Ambry Genetics, Invitae Genetics, Myriad Genetics

Other Relationship: Susan G. Komen for the Cure (I), AACR, Diane Helis Henry Medical Foundation (I), James P. Wilmot Foundation (I), Adrienne Helis Malvin Medical Research Foundation (I), Breast Cancer Research Foundation, Facing Our Risk of Cancer Empowered
Maria C. Katapodi

Research Funding: Swiss Cancer League, Swiss National Science Foundation

\section{Sandhya Pruthi}

Patents, Royalties, Other Intellectual Property: Mytonomy partnership (Inst)

\section{Carolyn D. Runowicz}

Honoraria: UpToDate

Patents, Royalties, Other Intellectual Property: Patent for "High efficacy anticancer drug delivery, release and nanoscale heat treatment of cancerous cells" (Inst)

No other potential conflicts of interest were reported. 


\section{Models for Calculating Breast Cancer Risk}

There are a number of statistical models that estimate an individual's absolute risk - the probability of developing breast cancer over a given time (https://epi.grants.cancer.gov/cancer_risk_prediction/breast.html\# absolute). In general, these risk models are well calibrated (ie, they have the ability to determine the proportion of women in the population who will develop cancer), but they have modest discriminatory accuracy (ie, they have the ability to determine whether a woman will or will not develop cancer)

The two most frequently used models in the United States for determining whether endocrine prevention should be discussed are the National Cancer Institute Breast Cancer Risk Assessment Too (BCRAT) based on the Gail model (https://bcrisktool.cancer.gov) and the International Breast Intervention Study (IBIS) Breast Cancer Risk Assessment Tool. The BCRAT provides 5-year and lifetime (up to age 90 years) estimated breast cancer risk and similar estimates for a woman the same age and race/ethnicity who is at average risk of getting breast cancer.

The BCRAT incorporates information on age, race, breast biopsy, atypical hyperplasia reproductive factors, and first-degree relatives to provide a 5-year and a lifetime risk (Gail MH, et al: J Natl Cancer Inst $81: 1879-1886,1989)$. However, it is not the tool of choice in women with the following: an extensive family history of breast cancer, a paternal lineage of cancer, a diagnosis of lobular carcinoma in situ, or inheritance of a germ line variant associated with high cancer risk or atypical hyperplasia. The BCRAT has been validated in a large diverse population of US women (African American, Hispanic, or Asian/Pacific Islander) age 35 years or older, and in some European populations (Banegas MP, et al: J Natl Cancer Inst 109, 2016; Costantino JP, et al: J Natl Cancer Inst 91:1541-1548, 1999; Decarli A, et al: J Natl Cancer Inst 98:1686-1693, 2006; Gail MH, et al: J Natl Cancer Inst 91:1829
1846, 1999; Gail MH, et al: J Natl Cancer Inst 99:1782-1792, 2007; Matsuno RK, et al: J Natl Cancer Inst 103:951-961, 2011; Rockhill B, et al: J Natl Cancer Inst 93:358-366, 2001). The BCRAT may underestimate risk in black women with previous biopsies (Gail MH, et al: J Natl Cancer Inst 99:1782-1792, 2007), Hispanic women (Banegas MP, et al: J Natl Cancer Inst 109, 2016) born outside the United States, and women with atypical hyperplasia (Pankratz VS, et al: J Clin Oncol 26:5374-5379, 2008)

The IBIS Breast Cancer Risk Assessment Tool (http://www.emstrials.org/riskevaluator/) has been validated in both average-risk and higher-risk populations in the United States (Brentnall AR, et al: JAMA Oncol 4:e180174, 2018; Amir E, et al: J Med Genet 40:807-814, 2003; Terry MB, et al: Lancet Oncol 20:504-517, 2019) but not in specific ethnic subgroups. The tool provides both 10 -year and lifetime breast cancer risk (for patients up to age 85 years). It requires more time than the BCRAT to complete because it incorporates reproductive factors, body mass index, height, information on affected second- and third-degree relatives, and lobular carcinoma in situ, atypical hyperplasia, hormone therapy, and breast density. IBIS performance is better than BCRAT performance in women with a family history of breast cancer (Amir E, et al: J Med Genet 40:807-814, 2003; Terry MB, et al: Lancet Oncol 20:504-517, 2019; Warwick J, et al: Breast Cancer Res 16:451, 2014). Unlike the BCRT model, it may overestimate breast cancer risk in women with atypical hyperplasia (Boughey JC, et al: J Clin Oncol 28:3591-3596, 2010). The concern has been addressed in Version 8 of the model but needs to be validated. To incorporate breast density into the latest version of the model requires the use of Volpara Volumetric Density (commercial software to calculate mammographic density). Breast Imaging Reporting and Data System (BI-RADS) data can also be entered, but this is based on percent density that was reported before 2013 . Additional validation is needed for the latest model that includes breast density.

TABLE A1. Pharmacologic Interventions for Breast Cancer Risk Reduction Expert Panel Membership

Name

Affiliation/Institution

University of Kansas Medical Center, Kansas City, KS

Carol J. Fabian (co-chair)

Sidney Kimmel Comprehensive Cancer Center and Johns Hopkins Medicine, Baltimore, MD

Elissa Bantug

Abenaa M. Brewster

University of Texas MD Anderson Cancer Center, Houston, TX

Nancy E. Davidson

Fred Hutchinson Cancer Research Center and University of Washington, Seattle, WA

Andrea DeCensi

National Hospital E.O. Ospedali Galliera S.C. Oncologia

Medica, Genoa, Italy, and Queen Mary University of London, United Kingdom

\begin{tabular}{lll}
\hline Justin D. Floyd & Cancer Care Specialists of Illinois, Swansea, IL & Community medical oncology \\
\hline Judy E. Garber & Dana-Farber Cancer Institute, Boston, MA & Medical oncology/cancer genetics \\
\hline Erin W. Hofstatter & Yale Cancer Center, New Haven, CT & Medical oncology \\
\hline Seema A. Khan & $\begin{array}{c}\text { Northwestern University Feinberg School of Medicine, } \\
\text { Chicago, IL }\end{array}$ & Surgical oncology \\
\hline
\end{tabular}

Maria C. Katapodi

University of Basel Nursing Science, Faculty of

Medicine, Basel, Switzerland

\begin{tabular}{ll}
\hline Sandhya Pruthi & Mayo Clinic Cancer Center, Rochester, MN \\
\hline Rachal Raab & Cancer Care of Western North Carolina, \\
Asheville, NC
\end{tabular}

Carolyn D. Runowicz

Herbert Wertheim College of Medicine, Florida International University, Miami, FL

Mark R. Somerfield

American Society of Clinical Oncology, Alexandria, VA
Expertise

Medical oncology

Patient representative

Breast cancer prevention

Medical oncology

Medical oncology

Oncology nursing

Primary care/internal medicine

Community medical oncology/member

of Practice Guideline

Implementation Network

Gynecologic oncology

Practice guidelines staff/health research methods 